\title{
The role of European «ro-ro» port terminals in the automotive supply chain management
}

\author{
J.C. Quaresma Dias ${ }^{\mathrm{a}, *}$, J.M.F. Calado ${ }^{\mathrm{b}}$, M.C. Mendonça ${ }^{\mathrm{c}}$ \\ ${ }^{a}$ CENTEC/ISEL - Instituto Superior de Engenharia de Lisboa, Polytechnic Institute of Lisbon, Mechanical Engineering Department, Rua Conselheiro Emídio Navarro, 1959-007 \\ Lisboa, Portugal \\ ${ }^{\mathrm{b}}$ IDMEC/ISEL - Instituto Superior de Engenharia de Lisboa, Polytechnic Institute of Lisbon, Mechanical Engineering Department, Rua Conselheiro Emídio Navarro, 1959-007 \\ Lisboa, Portugal \\ ' IPCDVS/Faculdade de Psicologia e Ciências da Educação, University of Coimbra, Rua do Colégo Novo Apartado 6153, 3001-802 Coimbra, Portugal
}

\section{A R T I C L E I N F O}

\section{Keywords:}

Automotive supply chain management

Short sea shipping

ro-ro Port terminals

Logistics postponement

Decoupling points

Cars transportation

\begin{abstract}
A B S T R A C T
The aim of this paper is concerned with the design and development of a functional framework for maritime mode integration in European automotive supply chain management when considering outbound distribution. Furthermore, it provides a readjustment of traditional concepts and terminology with findings that the role of ro-ro port terminals should be considered as decoupling points, poles and postponement platforms. Case studies examine relevant Western European ro-ro port terminals for cars and respective links to assembly/factories of vehicles localized in the hinterland and concludes that ro-ro port terminals reduce logistical friction and impedance, as well as promote space/time compression.
\end{abstract}

(c) 2008 Elsevier Ltd. All rights reserved.

\section{Introduction}

In recent years much attention in the research literature has focused on global and systemic supply chain management (SCM), related theory, concepts, sources of competitive advantage for firms and so on (Closs and Mollenkopf, 2004). Many of these research studies are based on practical studies, analysis and evidence related to automotive supply network (Küchlin and Sinz, 2000; Choi and Hong, 2002; Hines et al., 2002; Fredrikson and Gadde, 2005; Holweg et al., 2005a,b). A generic supply chain (SC) can be assumed like an organization of relatively enduring inter-firm, cooperative and collaborative entities, using resources from participants with consistent interests (Lee, 2004). Under such a paradigm the members of a SC share equitable risks, expenses and benefits to accomplish shared information and strategic quality systems whose goals are independent for each one of them (Ketchen and Giunnipero, 2004).

In the automobile industry and corresponding SCM there are significant frameworks of strategic operations in several areas like procurement, management of materials, production, factoring, general distribution and final transportation to markets. This kind of industry is an illustrative example of global operations and logistics supply demand-chain, pulled upstream by the customers from an outbound decoupling point (DP) (Christopher, 2000) or from an order penetrating point (OPP) (Olhager, 2003). In distribution, these

\footnotetext{
* Corresponding author. Tel.: +35 1933833913.

E-mail addresses: jdias@dem.isel.ipl.pt (J.C. Quaresma Dias), jcalado@dem.isel.ipl.pt (J.M.F. Calado), mclvmendonca@gmail.com (M.C. Mendonça).
}

global and strategic operations often encompass delayed differentiation or logistical postponement (Bowersox and Closs, 1996).

However, the integration of transportation and the respective contribution to the competitive advantage of automotive SCM, inbound and outbound, have been neglected in contemporary research; papers are rare and not focused on this new emerging topic. There are also few research studies about the integration of maritime transportation, especially short sea shipping (SSS) in the automotive SCM. There is even less research about car carriers and the role of roll-on/roll-off (ro-ro) car port terminals as relevant interfaces into distribution channels to the end customers, through postponement operations (Skipworth and Harrison, 2006). Therefore, the present paper aims to provide some knowledge about the role of the ro-ro port infrastructures and SSS (not including transhipment operations) in Western European automotive supply chain management when considering the distribution of cars. The knowledge provided and the conclusions have been based on data collected from several information sources including key-informants interviews and surveys.

\section{An integrative and theoretical approach}

\subsection{The integration of SSS and ro-ro port terminals in automotive SCM; the minimization of frictional costs}

The inbound side of any supply chain (sometimes until the 2nd tiers network suppliers), corresponds to raw materials transportation usually made by heavy transportation modes. This means transportation by railway over long continental distances or, trans- 
portation by deep sea shipping over intercontinental distances between ports by mainline services through mega carriers (oceanic vessels). There are several kinds of vessels (Stopford, 1997): general cargo, bulk, dry, fluid tankers or container carriers according to the cargo type. The transportation among the several tier suppliers network and automotive focal plant assembly is made over short or long distances depending on the respective locations. Thus, rail, road or container vessel carriers are used for long distances; for short distances, railway, short sea shipping (SSS) and, especially, road trucks and trailers are mostly chosen for a flexible door-to-door (d2d) service (Johnson et al., 1998) often using multimodal or special intermodal services.

The inter-modality is a very important operation in transport management, especially in most cases of automotive SCM. There are several typical examples of intermodal transportation (Lambert et al., 1993; Torbianelli, 2000) and one of them is known as 'ro-ro' (roll-on/roll-off) because trucks or cars are driven onto and off the vessels. This paper considers ro-ro inter-modality, which is evident in port movements of new cars and vehicles (Evangelista and Morvillo, 2000), and its relationship with the outbound inventory of automotive supply chain; in special port terminals the cars are driven on or off special vessels called car carriers (Mendonça and Dias, 2007). Car carriers, according to Johnson et al. (1998) can be described as follows: "ro-ro vessels are somewhat like large, floating parking lots. They have large doors in their sterns or on their sides. Ramps are used to carry and are stretched to the shore and cargo is moved on or off to the ship in trailers". Fischer and Gehring (2005) describe in detail the planning of vehicle transhipment in a seaport automobile terminal using a multi-agent system. In addition to this, car carriers consist of four, five, six or more parking grounds with capacity up to eight thousand cars or more. Ro-ro ships have an important advantage: flexibility; however, they need a demanding stevedoring operation to hold cars on or off the decks (Stopford, 1997). Geographical definitions encountered for SSS, embrace ports located along the coastal area of European Union (EU) and non-EU countries (including islands) from the
Barents Sea and Scandinavia, via the North and the Baltic Seas, down to the Mediterranean, including also some Northern African ports and the Black Sea (Paixão and Marlow, 2002). Thus, it makes sense to associate SSS with ro-ro maritime transportation of cars into European ports, linking focal automotive production with consumption markets.

From Naylor et al. (1999), Holweg (2003) or Holweg et al. (2005a,b), the integral model of the distribution segment has been improved (composed of the distribution echelon and retailer/dealer echelon lead-times adapted to the specific case of cars with utilization of ports), as depicted in Fig. 1. Thus, to calculate the total lead-time, the several transit times should be added up considering times from the gate release of car production to the end customer.

In order to improve the productivity gains in car distribution operations, a new practice $\mathrm{d} 2 \mathrm{~d}$ to the end customer (retailer or consumer or both, depending on circumstances) emphasising the role of ports, may be considered. Any strategic change must eliminate some hold-up and transit time operations, this being an important aim of the present study.

Nowadays, the operations and productivity gains are increasingly derived from added value achieved at terminals instead of emerging from the efficiency of transportation modes (Rodrigue, 1999). This is a typical issue of trade-off analysis (Rajeshkumar and Rameshbabu, 2006) and the respective evaluation plays a fundamental role in logistics management and automotive SCM. Thus, an example of trade-off analysis is concerned with having large scale transportation with high volumes of cargo, buffers management, etc. versus low frequencies and road transportation, $\mathrm{d} 2 \mathrm{~d}$, with low volumes of cargo and high frequency of departures and arrivals, enabling quick response to customer-demands. Therefore, if the SCM assumes the cost primacy of the transportation mode, ignoring or misunderstanding the role and costs of the warehouse platforms, it can cause the failure of the logistics system and also the failure of the element that was supposed to be optimized (Runhaar and Heijden, 2005). In spite of the importance of the origin and destination of freight movements, it is very important to

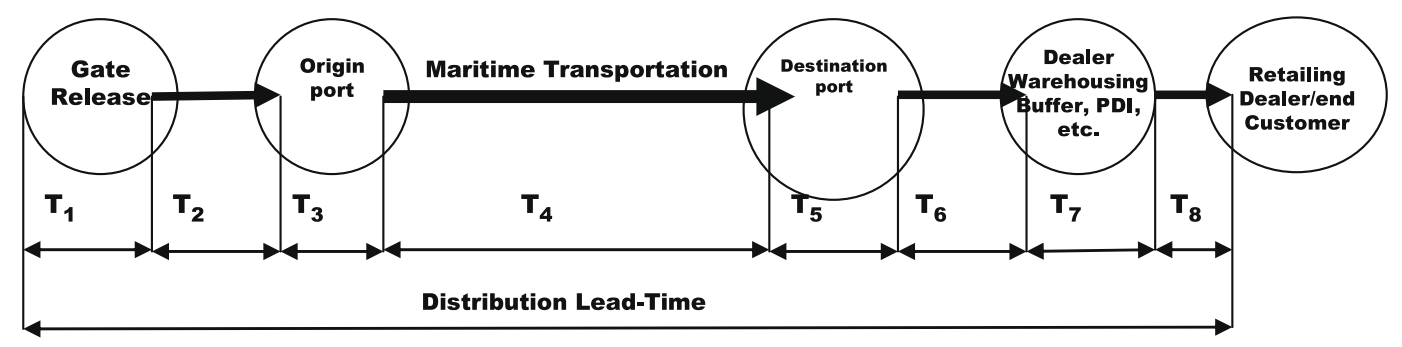

\begin{tabular}{|l|l|}
\hline$T_{1}$ & $\begin{array}{l}\text { hold-up time until gate release in the automotive plant assembly plus the time for the handling operations necessary for } \\
\text { land transportation (rail or road) }\end{array}$ \\
\hline$T_{2}$ & transit time between the gate release and the port terminal including the time for handling operations in the port terminal \\
\hline$T_{3}$ & hold-up time in the terminal of origin plus the time to board cars on plus hold-up time for the vessel to exit from port \\
\hline$T_{4}$ & $\begin{array}{l}\text { maritime transit time between origin and destination ports including the time for the cars to board off in the destination } \\
\text { port terminal }\end{array}$ \\
\hline$T_{5}$ & hold-up time in the destination terminal plus handling operations to land transportation \\
\hline$T_{6}$ & transit time to distribution centre and handling operations time \\
\hline$T_{7}$ & $\begin{array}{l}\text { hold-up time in the warehousing centre that includes transit time and PDI (Pre-Delivery } \\
\text { Inspection) operations time, postponement time, etc. }\end{array}$ \\
\hline$T_{8}$ & \begin{tabular}{l} 
the transit time to dealer and delivery time to end customer \\
\hline
\end{tabular} \\
\hline
\end{tabular}

Fig. 1. Traditional distribution lead-time. 
understand why and how the outbound inventory (the new cars) moves and how it is operated until it reaches the end customer.

Firstly, the inventory moves downstream in the supply demand-chain, subsequently pull or demand-driven (Min and Galle 1999). Furthermore, a ro-ro port terminal (to import) should be located as near as possible to market dealers and, simultaneously as near as possible to car production assembly factories (to export) allowing car import and export using the same vessel (car carrier).

Secondly, the inventory tends to move in the direction of minimum impedance. The concept of space/time impedance or friction (Hesse and Rodrigue, 2004) as a summation of all frictional costs covering space over time is central to many geographical considerations of economic and social processes; it corresponds to the impacts of distance, time and elasticity on freight flows.

Conventionally, this concept was subjugated to issues concerning distance, how to quantify it and transportation costs, being represented as a distance decay function. The most significant considerations of transport costs are related to the functions of composition, transhipment and decomposition which have been transformed by logistics. A higher level of inventory management (e.g. lean management) can lead to significant reduction in the logistical friction as well as terminal improvements decreasing transhipment and/or cross-docking times and costs. In these conditions, time is becoming as important as distance in the assessment of transportation costs and impedance. Therefore, as transport costs went down through space/time convergence, the value of time went up proportionally (Hesse and Rodrigue, 2004). The most flexible among all modes of transport, the road truck, very often supplies 'Just-in-Time' (JIT) platforms of automobile production and assembly and the same supply chain uses the return journeys to send back packs or unload containers or pallets. It means that reverse operations logistics balances part of the costs of forward logistics reducing the impedance of the automotive SCM considered as a whole or a loop. In the automotive SCM the lowest level of impedance corresponds to the compression of space and time strategies. Thus, the reduction of, not only, several operational and transportation steps, but also buffering and idling time will lead to costs reduction. Furthermore, the inclusion of interfaces in integrated networks as for example logistics platforms could add value to the inventory or reduce value, by increasing or decreasing the impedance levels. In this case the difference between efficient and inefficient solutions depends on the relationship between strategic management and SCM best practices, competitive advantages, organizational performance (Li et al., 2004) and how logistics process can be improved. If logistics provides value-added services, firms are able to provide value-added activities (Bowersox and Closs, 1996).

This situation provides an important conjunction in outbound car distribution: scope and scale economies. The SSS maritime mode used for transportation of new vehicles shows that it can promote economies of scale (Evangelista and Morvillo, 2000) and the use of ro-ro port terminals can provide economies of scope if they can allow buffering, warehousing with pre-delivery inspections (PDI) and postponement customization (Mendonça and Dias, 2007); all this represents an emergent paradigm in automotive SCM. Thus, if ro-ro port terminals of automotive supply chain are something more than simple nodes of a complex network, as pointed out by several authors already mentioned, then, how should this kind of port terminals be classified?

From a transport perspective, Marlow and Casaca (2003), refer to them as links, interfaces and nodes that in international distribution channels are often ports. They also assume that ports are nodes where logistics operations take place; but if it is considered that in such nodes, logistic operations take place, then, it should be assumed that these ports perform operations which add value.
Furthermore, it is desirable to test if some special ro-ro port terminals could work as a decoupling point (DP) of an automotive SC, because upstream of the DP lean supply chains are needed. On other hand, downstream of the DP agile supply chains are requested (Christopher, 2000). As a matter of fact Marlow and Casaca (2003), pointed out that new highest performance ports are lean and agile ports. In these conditions the ro-ro port terminal should not be classified as nodes, because they are not neutral points, but instead they should be classified as special attractive points adding value to the new cars and also meeting points between push and pull value chains.

\section{2. ro-ro Port terminals as DP of automotive SCM}

It is known that outbound inventory of automotive SCM - vehicles - and the respective flow of information moves toward a point, not a neutral node but a special point, provides an interface between the push value chain and the pull value chain. Christopher (2000) presented the DP as some place between supply chain forecast-driven and supply chain demand-driven. This special point (Yang and Burns, 2003) can provide sales with good visibility of the real demand and it should lie downstream in the supply chain, as near as possible to the final demand. Therefore, this point consists of a make-to-order strategy and defines a stage in the supply chain where a specific car is linked to a specific customer order (Olhager, 2003). This conceptual framework was considered by Naylor et al. (1999), who expressed a similar opinion, referring it as a stockholding DP with characteristics of the lean and agile paradigms. However, it is possible for two decoupling points to coexist (Christopher, 2000); one providing the last level of customization being located as downstream as possible and another functioning as an information decoupling point located as upstream as possible to ensure a reliable production forecast. The first one is a material point and the other one a virtual point or an informational decoupling point (Christopher, 2000).

Olhager (2003) refers to an order penetrating point (OPP) and distinguishes different manufacturing pre-OPP forecast-driven operations and post-OPP operations concerned with customer order-driven. However, the issue is not how far the order penetrates, but how far real demand is made visible (Christopher, 2000). In these conditions, the DP is the only point where inventory should be carried to in a generic form, where the final assembly or customization is undertaken. Consequently, the DP should be located as near as possible under real demand visibility. This aspect is crucial to the current study, determining the existence of one or two decoupling points (it is possible that one of them could be an OPP), their eventual coexistence and where they are located in the automotive SCM. Thus, customers request postponement or delayed differentiation (Bowersox and Closs, 1996; Su et al., 2005; Caux et al., 2006) being done in real time, could be a source of competitive advantage. However, in other analyzed cases, the point at which a product variant becomes specific in relation to a particular customer is moved to the assembly line upstream, as for instance in the case of Volvo (Fredriksson and Gadde, 2005). These authors suggest the combination between flexibility and robustness in order to be able to customize at reasonable costs. The desirable existence of a DP in the car distribution segment, promotes not only the possibility of delayed differentiation and customization, aimed in scale and scope economies, but also time compression (Christopher, 1998).

In an agile automotive supply chain, the strategic DP works like a postponement point (Christopher, 2000) and must include vehicles PDI and other customization operations. The postponement is based on the principle of seeking design and manufacture products using common platforms, components, or modules, but where customization does not take place until the final market destination 
and/or customer requirements are known (Christopher, 1998). In automotive SCM, the postponement is a vital element in an agile strategy; however, there are other advantages in postponement strategies. Firstly, inventory can be held at a generic level so there will be fewer stock-keeping variants and, hence, less inventory in total. Secondly, because the inventory is generic, its flexibility is greater, meaning that the same components, modules, or platforms can be embodied in a variety of end products; i.e. mass customization (Silveira et al., 2001). Thirdly, forecasting is easier at a generic level than at a level of finished items. This last point is particularly relevant in global markets where local forecasts will be less accurate than a forecast for worldwide volume. Furthermore, the ability to customize products locally is a glocalization phenomenon which is at the same time global and local and, hence, referred to as "glocal" (Dornier et al., 1998). It means that a higher level of variety may be offered at a lower total cost, enabling strategies of mass production to be pursued (Christopher, 2000).

The existence of two DP (one of them an eventual OPP) in the car distribution segment can absorb or reduce the bullwhip effect or order variance amplifications (Forrester, 1958, 1961; Chen and Paulraj, 2004). It refers to a phenomenon where the fluctuations in the order sequence are usually greater upstream than downstream in the SC. This effect of disruption in supply networks increases its complexity levels because small changes in demand can result in large variations in orders placed upstream. The existence of some forecasting errors in the several levels of coordination of automotive supply network can promote high levels of stocks (and costs) and the bullwhip effect might appear in different forms of inventory. The DP and the strategy of postponement can also contribute to the absorption of the bullwhip effect, uncertainty and complexity in the SC (Christopher, 2000; Olhager, 2003). Holweg et al. (2005a,b) demonstrate the benefits of SC collaboration and synchronization to minimize this effect.

\subsection{Theoretical constructs}

From the deductive literature review presented in the last section, the most significant theoretical assertions or constructs that shape in some way the integration of ro-ro port terminals into automotive SC, can be summarized as follows:

- Lead time compression and order fulfilment; space/time compression and cost reduction;

- Minimization of impedances and frictions;

- The strategic positioning of the DP and/or OPP and their eventual coexistence in the automotive SCM;

- Push and flexible inbound chain vs. pull and agile outbound chain;

- Agile logistics in car distribution; postponement, delayed differentiation and scope economies; SSS and intermodal solutions;

- Postponement platforms (the places where delay differentiation and PDI of the cars are operated) and ro-ro port terminals;

- Transportation networks; nodes and links.

\section{Significant questions and research methodology}

Based on the literature review and what is systematically observed in many Western European ports about the import and export of new vehicles, a set of significant questions will be framed. In spite of the fact that the European continent has a considerable number of ports, not all of them are appropriate to handle vehicles since they are goods of high added value that need specific intermodal (Bichou and Gray, 2005) ro-ro terminals (Torbianelli, 2000). Thus, the integration of ro-ro port infrastructure in the logistics channels that support vehicle industry, multiple supply chains is recommended. The European automotive supply chain (outbound distribution) will help us to find the reasons for this evidence. Then, in order to understand the problem and develop an adequate conceptual framework to achieve the goal of the present research, answers to the following set of significant questions (as Yin, 1994, proposed) concerned with the role of the ro-ro port terminals in outbound automotive SCM and how to embed theoretical propositions, should be found:

- 1st Question: Why ro-ro maritime transport adds value and competitive advantage, as well as fit in the outbound supply and into global automotive supply chains?

- 2nd Question: How can the particular connections, between roro port terminals and the outbound vehicles distribution logistics platforms, be characterized?

- 3rd Question: How can the particular connections, between roro port terminals and the outbound plant assembly gate releases to distribution tiers, be characterized?

In order to find answers to "how and why" questions (Yin, 1994) and to generate a theory, a theoretical approach was used following some recommendations, namely the process of inducting theory-building research and the multiple-case study (Eisenhardt and Graebner, 2007; Yin, 1994) as a method and strategy of direct/field research (Mintzberg, 1979). Empirical insight was sought and focused on some of the most important Western European roro ports where there are movements of vehicles exported from producers and the most important postponement logistics infrastructures (platforms) to the imported vehicles, linked to the same ports. A large set of European ports are equipped with significant ro-ro terminals and this situation allows a representative research sample. Thus, the goal of such sampling is to choose cases which are likely to replicate or extend the emergent theory (Eisenhardt, 1989). Therefore, it was decided to use multi-case studies as a replication research strategy (external validity), using similar protocols (Yin, 1994). The key-informants of relevant railways firms, road firms, car logistical operators, data, and other information of corporations and firms involved in research require anonymity. However, some brands of cars imported and exported through the ports are very well-known and for this reason, they appear without anonymity. In those conditions the relevant chain evidences, constructs and conclusions can be presented.

Multiple sources of evidence (ports authorities, logistics and transports operators, people responsible for departments of automotive production and logistical platform forwarders, etc.) were used, as well as the respective methodological triangulation (data, documents, perspectives, key-informants) and the creation of an indispensable chain of evidence. Pattern matching of data analysis provides internal validity and the use of multiple sources of evidence and the triangulation contributes to test the constructs' validity. The replication of several situations helped to achieve the reliability goal and minimization of errors and biases in the field of study. Those are the essential methodological aspects of the present research. In turn, the drawback is that the generalization to other contexts needs an appropriate demonstration. From the evidence collected and respective chain, a set of common characteristics in both import and export movements, have emerged.

The information and finding links between outbound logistics support platforms of vehicles distribution and automotive focal plants must provide a functional and theoretical framework to answer the questions quoted above and, hence, new knowledge is going to be obtained. The information acquired from outbound vehicles distribution postponement platforms and from automotive focal plants, with multi-case studies, must provide a functional and theoretical framework to answer the questions above and to obtain new knowledge. 


\section{Research findings; the core-evidence of the theory}

The study observes relevant ports equipped with significant roro terminals in Spain, Portugal, France, Italy, Belgium, Holland, Germany, Sweden, England and Ireland. In these European regions, most logistical car postponement platforms, focal plants assembly and/or manufacturing, imports and exports movements by maritime mode in those ports were also observed. Concerning ports with ro-ro terminals, the following have been considered: Vigo, Santander, Pasages, Barcelona, Sagunto, Setúbal, Le Havre, Livorno, Sheerness (Medway ports), Bristol, Copenhagen and Malmö, Göteborg, Emdem, Zeebruge/Ghent, Antwerp, Rotterdam. In these ro-ro terminals several solutions about concessionaries, logistical operators, ship-owners, stevedoring operators and postponement have been observed. Furthermore, the most relevant car factories refer to the most important brands found and localized in Europe are as follows: VW, Audi, Skoda, Seat, Opel, Renault, Fiat, Citroen, Ford, Nissan, Suzuki, Mitsubishi, Seat, Volvo, DaimlerChrisler, BMW, Toyota, Honda, and others.

The sample has been selected to try and achieve conclusions concerned with Western European sea ports, where the main activity is the short sea shipping of cars produced in plants located in the sea ports' hinterland. The aim was to achieve a sample of sea ports located close to the plants using them (export) and simultaneously close the markets (import) they are feeding. The sample includes sea ports with only one car terminal and others with several car terminals, where some are dedicated to specific car manufacturers. Most of the sea ports included in the sample considered offer as logistics activities, pre-delivery inspection (PDI) and repairs of damage which occurred during transportation or/and damage which occurred during stevedoring operations. It has been observed, that further postponement operations are performed according to the manufacturers policies and sometimes aiming to fulfil a request from an important costumer. According to the data collected from several sources of information, Table 1 presents information about the annual new car volumes moved through SSS in 2007, via each port selected, as well as by car makers using a specific sea port.

The research findings in the multi-case analysis mentioned above can be summarized as follows:
$F_{1}$. The ro-ro terminals dispose of a parking area that works as a buffer area: The ro-ro port terminals studied being a meeting point between customer-demand and dealer-forecast, evidence that the volume of cars and hold-up time must be as low as possible. These characteristics coincide with the material and strategic concept of decoupling point (DP) recognized by the literature. These terminals cannot coexist with polluting goods terminals like, for example coal terminals, because of potential damage to the exterior painted surfaces of new cars.

$F_{2}$. The logistical platforms of vehicles postponement are always into the ro-ro port terminal close to the buffer (there is one exception - the port of Setúbal): This solution configures a space/time compression and minimization of impedances with cost reductions. The positioning of these infrastructures as near as possible but outside the terminals is a historic situation in ro-ro port terminals (case illustrated by the port of Setúbal). In the new solutions, the postponement logistical platforms of vehicles are located within the ro-ro port terminal by the port authorities consigning these terminals to logistical operators or consortia (logistics operators or a ship owner and line maritime operator or a land rail and/or road transport operator) who have contracted the distribution of the cars with the respective car company brands. This solution gives stability and contributes to a more predictable environment for all partners and players involved.

$F_{3}$. By outsourcing or consignation, some port logistic operators manage simultaneously, the factory gate release and the transportation operations. Sometimes some operations are performed through of a third party logistics provider $(3 \mathrm{pl})$ contracted by the distribution channel leader: This allows, considering the position of the second virtual and informational point, only an Order Penetration Point (OPP) not a material or decoupling point in the interface focal factory/gate release. The ro-ro terminals of the European ports analyzed are close to one, two or more factories or focal plant assemblies which export vehicles through those ports.

$F_{4}$. These entities or consortia of operators works as a $3 p l$ of one brand or few and they are certified by the manufacturers to make PDI, repairs of damages, postponement operations of customization (e.g. specific paints, supply equipment, etc.) to the import move-

Table 1

Annual new car volumes moved through SSS.

\begin{tabular}{|c|c|c|c|c|c|}
\hline \multirow[t]{2}{*}{ Sea ports } & \multicolumn{2}{|l|}{ Import } & \multicolumn{2}{|l|}{ Export } & \multirow[t]{2}{*}{ Total } \\
\hline & Brands & Cars & Brands & Cars & \\
\hline Vigo & Several brands & 452,959 & Citroën; Peugeot & 106,144 & 559,083 \\
\hline Santander & Honda; Mitsubishi; VW & 92,466 & Renault; Toyota; VW & 228,702 & 321,168 \\
\hline Pasage & Ford; Opel & 83,606 & Opel; VW & 219,128 & 302,734 \\
\hline Barcelona & Fiat; Mazda; Mitsubishi; Nissan; Suzuki; VW & 353,457 & Ford; Mercedes; Renault; Seat; Suzuki; VW & 447,949 & 801,406 \\
\hline Sagunto/Valencia ${ }^{a}$ & Fiat; Toyota & 470,673 & Ford; and others & 285,754 & 756,427 \\
\hline Setubal & Several brands & 82,073 & Mitsubishi, VW & 111,399 & 193,472 \\
\hline Le Havre ${ }^{\mathrm{b}, \mathrm{c}}$ & Citroën; Peugeot; VW; and others & - & Citroën; Peugeot; Renault; and others & - & - \\
\hline Livorno & VW; and others & 193,310 & Fiat; and other brands produced in Italy & 212,921 & 406,231 \\
\hline Sheerness & Ford; Honda; Subaru; VW & 20,000 & Citroën; Peugeot; VW group; and others & $-{ }^{\mathrm{b}}$ & $400,000^{d}$ \\
\hline Bristol $^{\mathrm{e}}$ & GM; Honda; Mitsubishi; Suzuki; Toyota & $-\mathrm{b}$ & GM; Honda; Jaguar; Land Rover; Toyota & $-{ }^{\mathrm{b}}$ & $650,000^{\mathrm{d}}$ \\
\hline Copenhagen/Malmoe & BMW; Citroën; Ford; Opel; Peugeot; VW; and others & $-\mathrm{b}$ & Volvo; VW; and others & $-{ }^{b}$ & 518,000 \\
\hline Goteborg & Several brands & $231,000^{d}$ & Volvo; and others & $82,000^{d}$ & $313,000^{d}$ \\
\hline Emden & VW; and others & $-\mathrm{b}$ & AUDI; BMW; Honda; Porsche; VW & $-{ }^{\mathrm{b}}$ & $-\mathrm{b}$ \\
\hline Zeebrugge/Ghent ${ }^{\mathrm{C}}$ & Ford; Honda; Nissan; Toyota; and others & $1,030,324$ & Ford; Toyota; Volvo; and others & $1,178,582$ & $2,208,906$ \\
\hline Antwerp & VW; and others & 314,995 & Ford; and others & 625,478 & 940,473 \\
\hline Rotterdam $^{c}$ & Mercedes and others & $741,700^{t}$ & Several brands of German production & $803,600^{t}$ & $1,545,300^{t}$ \\
\hline Bremen & AUDI; VW; and others & 794,983 & Mercedes; VW & $1,277,846$ & $2,072,829$ \\
\hline
\end{tabular}

a Values of 2006

b Values not available.

c Includes deep sea.

d Approximate values.

e Includes transhipment

t Only available in metric tons. 
ments. This solution provides a relevant cost reduction since the investment made by the car makers and port operators is not repeated by a large set of dealers dispersed in a region. Concerning ro-ro loading on and off, the respective terminal logistics operator assigns the adequate number of driver stevedores and other personnel to shackle or unshackle each vehicle carefully in the deck-floor of the vessel. This solution also configures a space/time compression and minimization of impedances and frictions with reduction of costs, namely, the port handling costs. Concerning car operations, after the ship arrival, each car is inspected and if there is evident transportation damage the repair is performed immediately; afterwards the car is driven to the buffer. Some days latter, an order is requested from the central dealer (because in the local agency or point of sales - POS- is face to face with end customer) to these platforms into ro-ro ports. If there are no special customization needs, the car with the characteristics requested by customer (colour, model, etc.) is submitted to the PDI and, afterwards, the logistics operator sends it to the POS (the logistics operator of the ro-ro port terminal is responsible for transport operations) by road transportation in a d2d operation. Within a few hours, or a day at the maximum, the car is delivered to the customer. If any customization operation is necessary, the order fulfilment can be delayed by one or two more days.

$F_{5}$. The majority of the ports analyzed try to achieve a balance between import and export costs and quantities of cars. The balanced situation configures a minimization of impedances and frictions with reduction of freight costs to all partners: importers, exporters and car manufacturers. Few countries import more cars than export as they consume more than they produce and do not achieve a desirable equilibrium.

\section{Propositions and functional framework}

\subsection{Theoretical propositions}

The ro-ro port terminals studied, considering only the SSS segment, being a meeting point between customer-demand and dealer-forecast, show that the volume of cars and hold-up time must be as low as possible, to reduce costs. With the utilization by automo- tive supply chains of port terminals as tools of impedance minimization and time/space compression, through intermodal and ro-ro cars operations, brands can also reduce costs.

The port can be seen not only as DP of automotive supply chain through the utilization of ro-ro terminals (as postponement and PDI platform), but also as a car buffer and "shock absorber" between customers-demand and dealers-forecast. Consequently, through this strategic management of distribution in the automotive supply chain, an emergent paradigm has been observed: if the distribution to the end customer is made through the port logistics operator, then, the main role of the car dealers will be customer relationship management (CRM), specifically, sales and post-sales operations.

This set of constructs explains the reason why only some ports integrate SSS in global automotive supply chain; the closeness of important vehicle factories with special railroad links balances the maritime freight, reducing substantially both import and export costs and allowing minimization of the unloaded return transportation (Fig. $2-\mathrm{C}_{4}$ ).

The transport modes (road truck and railway) from automotive focal factories to distribution and postponement logistics platforms also tend to minimize the empty journeys with the cars imported through the ro-ro port terminal. This advantage reduces friction costs and impedance, promotes space-time compression, and adds value by compressing several transit times $\left(C_{1} ; C_{2} ; C 3\right.$; $\mathrm{C}_{5} ; \mathrm{C}_{6}$ ). The transit time to distribution centre and handling operations is unnecessary because the hold-up time in the warehousing centre and PDI (pre-delivery inspection) are made in the port installations $\left(C_{3}\right)$.

Finally, the port ro-ro terminal is the origin of the last transit time before the dealer, which is the delivery destination for the end customer (Fig. 2). When this lead-time is compared with the lead-time showed in Fig. 1, a significant lead-time reduction can be observed.

These conditions together with multimodal and intermodal infrastructure that link the ports and factories promote agility in the outbound automotive supply chain and join both scale and scope economies to this global network and strategic quality orientation to the end customer. All these strategic factors promote

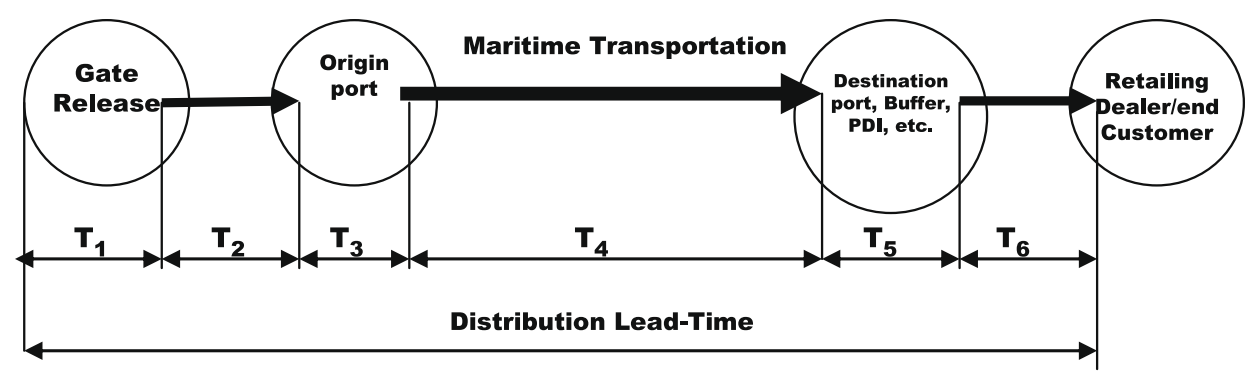

\begin{tabular}{|c|c|}
\hline$T_{1}$ & $\begin{array}{l}\text { hold-up time until gate release in the automotive plant assembly plus the time for the handling operations necessary } \\
\text { for land transportation (rail or road) }\end{array}$ \\
\hline $\mathbf{T}_{2}$ & $\begin{array}{l}\text { transit time between the gate release and the port terminal including the time for handling operations in the port } \\
\text { terminal }\end{array}$ \\
\hline $\mathbf{T}_{3}$ & hold-up time in the terminal of origin plus the time to board cars on plus hold-up time for the vessel to exit from port \\
\hline $\mathbf{T}_{4}$ & $\begin{array}{l}\text { maritime transit time between origin and destination ports including the time for the cars to board off in the } \\
\text { destination port terminal }\end{array}$ \\
\hline $\mathbf{T}_{5}$ & hold-up time in the destination terminal plus handling operations to land transportation \\
\hline $\mathbf{T}_{6}$ & the transit time to dealer and delivery time to end customer \\
\hline
\end{tabular}

Fig. 2. New paradigm distribution lead-time. 
competitive advantage to the vehicle supply chain and qualify the port terminals. It is evident that the difference between the eight operations presented in Fig. 1 and only six operations presented in Fig. 2, represents a significant compression of space/time resulting in added value. Usually a port can be classified like a neutral point, a 'node' of several networks and channels promoting synchronization of flows and transport systems integration (land and sea) (Rodrigue, 1999). The characterization of the phenomena presents the ports' needs trying to link up with the trade logistics platforms as nodes of the big chartering companies (Perez-Labajos and Blanco, 2004).

Therefore, ro-ro maritime transport fits in worldwide supply chains of automotive production because some special ports add value and competitive advantage by offering economies of scale to the distribution, being the outbound side of the global automotive supply chains. These conditions can be considered as logistical attractiveness. Based on theoretical aspects mentioned above, integrated approach and the data collected through the constructs and findings of case/field research, some overall propositions can be inducted:

$P_{1}$. Ro-ro port terminals utilized in global automotive supply and value chains are not neutral points - nodes - but attractive points or source of competitive advantage. This kind of network point or special node generates logistical attractiveness and work like (positive) magnetic poles and each one of them can be named a 'pole' or a 'logistical pole'. Nodes are neutral points in the respective networks and logistical poles formed by ro-ro port terminals are sources of competitive advantage in the corresponding value networks. In these conditions nodes and poles are not the same concept and the following conclusion may be proposed:

\section{Node + Logistical Attractiveness $=($ Logistical $)$ Pole}

$P_{2}$. Based on the concept of logistical pole, production vehicles platform/ro-ro port terminal and ro-ro port terminal/postponement logistical platform configure two dipoles in global automotive supply and value chains, and make bipolarities which can be named "logistical bipolarities" One of them, "ro-ro port terminal/postponement logistical platform" is a conjunctive bipolarity, because one pole, the ro-ro port terminal, is combined with postponement platforms, in the same place or space.

$P_{3}$. In the outbound segment of the automotive supply chain, a logistical bipolarity is a phenomenon of global logistics network and value attractiveness. Thus, the flows in the ro-ro port termi- nal are not only, a neutral phenomenon of flows between two nodes with low friction cost and low impedance but also an outbound logistics of agile automotive chains.

$P_{4}$. The optimization of two dipoles (not two nodes) and respective trade-off management induces and improves optimization in the outbound segment of the automotive supply chain and works like an integrated system. The logistical dipoles being automotive factories/assembly and ro-ro port terminals, form a distribution network of vehicles (import and export) which work as an integrated system.

$P_{5}$. Ro-ro port postponement terminals in Western Europe are simultaneously DP of automotive SCM and logistical poles. As consequence of the P5 (Fig. 3), the segment of automotive value chain between DP and OPP can be seen as a push and pull mix. The DP is placed into ro-ro destination port terminal, as near as possible to the POS. The OPP is placed in the interface gate release/cars factory assembly, offering a good visibility of real demand as far upstream as possible. Between the OPP and the DP, as well as between the interface factory assembly/gate release and the destination ro-ro port terminal, the value chain is simultaneously driven by forecasting and driven by demand (push and pull).

\subsection{Functional framework}

The first, second, third propositions provide the answer to the previous first significant question "Why does ro-ro maritime transport add value and competitive advantage and fit in the outbound supply of the global automotive SC?"

Only the ports that provide logistical bipolarities with factories of automotive production, integrating SSS (ro-ro) provide logistical attractiveness to the terminal because they allow added value to the imported vehicles distribution in the same vessel. These concepts of logistical attractiveness and the formation of bipolarities, also presented in the first, second and third propositions, answer the previous second significant question "how can the particular connections between ro-ro port terminals and the outbound logistics support platforms of vehicles be characterized"?

It has been observed that these connections must be classified as logistical bipolarities. The conjunctive poles characterizing the connection between ro-ro port terminals and car postponement terminals plus the focal cars factory production/assembly plant in the port hinterland form the logistical bipolarity.

Fig. 4 presents the generic functional framework of logistical dipoles formation integrating SSS in automotive distribution SCM. The ro-ro port terminals are links or interfaces. However, in both cases they are logistics platforms because they allow competitive advan-

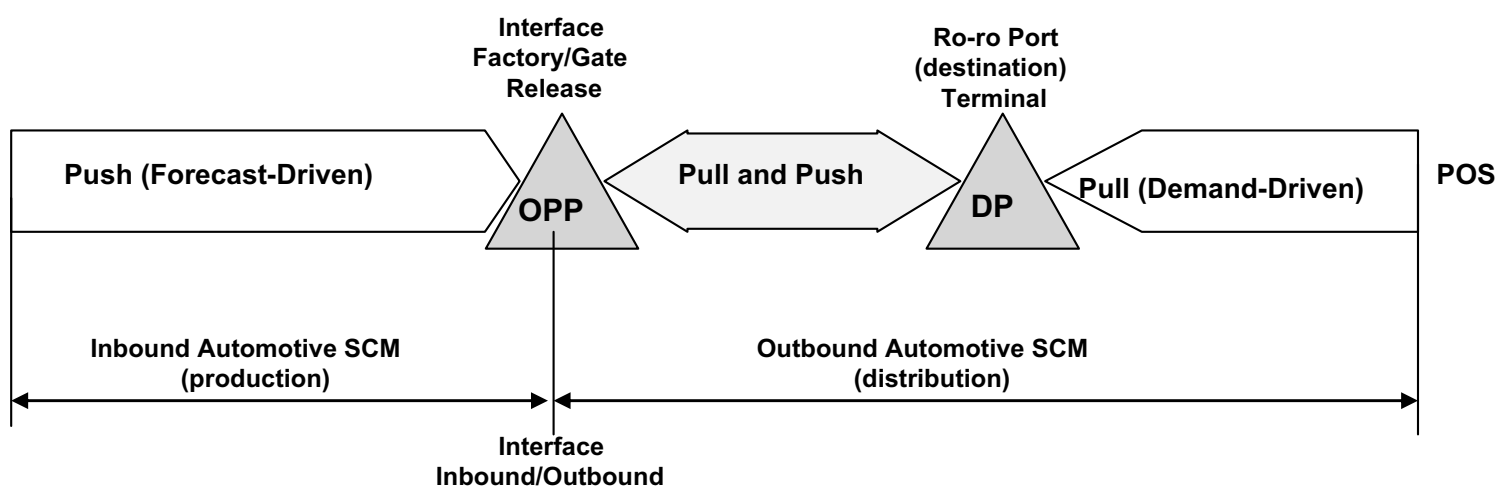

Fig. 3. OPP and DP into outbound automotive SCM (cars distribution). 


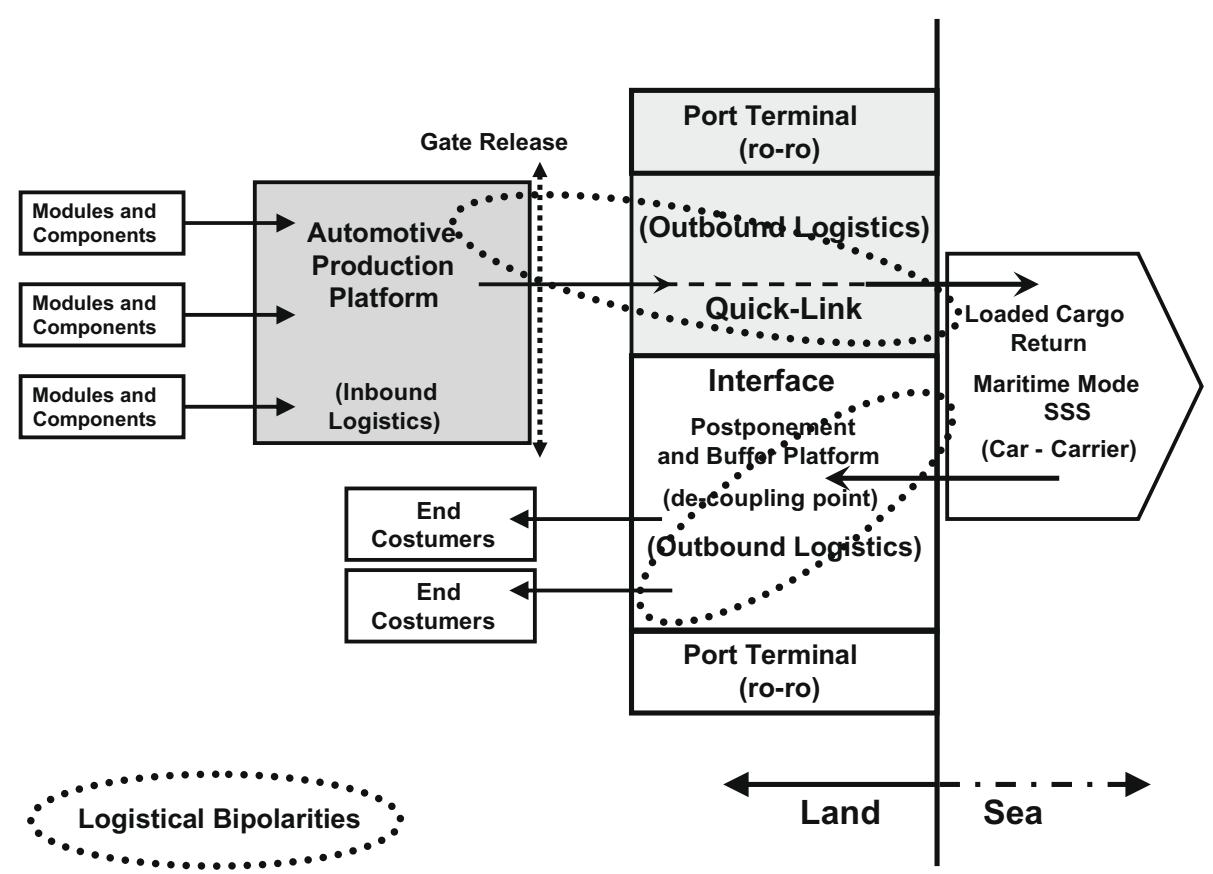

Fig. 4. Maritime mode integration in the automotive SCM and logistical bipolarities.

tage by adding logistics value through time compression (quicklinks) or/and production postponement operations (interfaces). This functional model shows the ro-ro port terminal as a conjunctive pole of car outbound distribution in importing movements. One pole is formed by the postponement platform for importing which gives to the port an interface mission since it adds value by typical production and customization operations. Another one is the export function of ro-ro terminal that gives the port a quick-link mission, because it adds value by typical time compression.

The set of four propositions answer the previous third significant question "How can the particular connections between ro-ro port terminals and the outbound gate releases of plants assembly to distribution tiers be characterized"?

The answer is given by the link of two poles that form a logistic dipole or logistical bipolarity. This bipolarity is formed by the ro-ro port conjunctive pole and the gate releases of automotive production/assembly factories. Logistical attractiveness fits value through bipolarities. This model shows that port ro-ro terminals provide maritime transports (SSS) integrated in the logistical services of automobile production and consumption. It occurs wherever it is possible to set up links with production lines and consequent export flow, through the formation of a bipolarity balanced with other bipolarity on the outbound side, with import flow platforms with minimized buffer zones that work as an OPP in SCM.

Finally, management systems may vary but, in all cases, the flow through these installations is regulated by downstream customer's requirements, which has been discussed previously as a pull factor. This was demonstrated case by case as a common pattern of multipolar formation and was consistently replicated by internal validation.

\section{Conclusions}

The results of the research have shown that ro-ro port infrastructures already play a new role in cars distribution channels. They can be seen as a D, which is the last physical tier until the end customer and simultaneously a logistical platform of postponement. These port terminals improve cost reduction through time and space compression in the distribution of automotive SC.
This empirical research validates the previous theoretical propositions and the present paper has contributed to the distribution operations literature, namely in the European automotive SCM. Perhaps its main contribution is to cover the gap concerning integration of the maritime mode and, consequently the new role of ro-ro port terminals in those value chains. Furthermore, it does not exclude the possibility that the formation of logistical dipoles, seen here as an instrument for integration of the maritime mode in outbound automotive SCM, may be extended to other functions or other modes. Such a formation may even be valid for other spaces within Europe, or even for different types of merchandise such as containers, bulk or several general cargos. However, in turn, it is possible that any generalization or adaptation of the present theoretical framework to other contexts would require both a new theoretical demonstration and empirical validation through new specific studies.

\section{References}

Bichou, K., Gray, R., 2005. A critical review of conventional terminology for classifying seaports. Transportation Research Part A: Policy and Practice 39 (1), 75-92.

Bowersox, D., Closs, D.J., 1996. Logistical Management, the Integrated Supply Chain Process, International ed. McGraw-Hill. Chapter 3, pp. 78-82; Chapter 16, pp. 471-475.

Caux, C., David, F., Pierreval, H., 2006. Implementation of delayed differentiation in batch process industries: a standardization problem. International Journal of Production Research 44 (16), 3243-3255.

Chen, I.J., Paulraj, A., 2004. Understanding supply chain management: critical research and a theoretical framework. International Journal of Production Research 42 (1), 131-163.

Choi, Thomas Y., Hong, Yunsook, 2002. Unveiling the structure of supply networks: case studies in Honda, Acura, and DaimlerChrysler. Journal of Operations Management 20 (5), 469-493.

Christopher, M., 1998. Logistics and Supply Chain Management; Strategies for Reducing Cost and Improving Service, second ed. Financial Times, Prentice Hall. Chapter 1, pp. 25-26; Chapter 9, pp. 269-271.

Christopher, M., 2000. The Agile Supply Chain Competing in Volatile Markets. Industrial Marketing Management 29 (1), 37-44.

Closs, D.J., Mollenkopf, Diane A., 2004. A global supply chain framework. Industrial Marketing Management 33, 37-44.

Dornier, P.P., Ernest, R., Fender, M., Kouvelis, P., 1998. Global Operations and Logistics - Text and Cases. John Wiley and Sons Inc., Berlin. Chapter 8, pp. 252 257; Chapter 12, pp. 441-442. 
Eisenhardt, K.M., 1989. Building theories from case study research. Academy of Management Review 14 (4), 532-550.

Eisenhardt, K.M., Graebner, Melissa E., 2007. Theory building from cases: opportunities and challenges. Academy of Management Journal 50 (1), 25-32.

Evangelista, P., Morvillo, A., 2000. Maritime transport in the Italian logistics market. Maritime Policy Management 27 (4), 335-352.

Fischer, T., Gehring, H., 2005. Planning of vehicle transhipment in a seaport automobile terminal using a multi-agent system. European Journal of Operational Research 166, 726-740.

Forrester, J., 1958. Industrial dynamics. Academy of Management Review 7, 49-58.

Forrester, J., 1961. Industrial dynamics. Harvard Business Review, 37-66.

Fredriksson, P., Gadde, Lars-Eric, 2005. Flexibility and rigidity in customization and build-to-order production. Industrial Marketing Management 34, 695-705.

Hesse, M., Rodrigue, J.-P., 2004. The transport geography of logistics and freight distribution. Journal of Transport Geography 12 (3), 171-184.

Hines, Peter, Silvi, Riccardo, Bartolini, Monica, 2002. Demand chain management: an integrative approach in automotive retailing. Journal of Operations Management 20, 707-728.

Holweg, M., 2003. The three-day car challenge: investigating the inhibitors of responsive order fulfilment in new vehicle supply systems. International Journal of Logistics: Research and Applications 6 (3), 165-183.

Holweg, M., Disney, S.M., Hines, P., Naim, M.M., 2005a. Towards responsive vehicle supply: a simulation-based investigation into automotive scheduling systems. Journal of Operations Management 23, 507-530.

Holweg, M., Disney, S.M., Holmström, J., Småros, J., 2005b. Supply chain collaboration: making sense of the strategy of continuum. European Management Journal 23 (2), 170-181.

Johnson, J., Wood, D.F., Wardlane, D., Murphes, I.P.R., 1998. Contemporary Logistics, seventh ed. Prentice Hall. Chapter 6, pp. 177-200.

Ketchen, D.J., Giunnipero, L.C., 2004. The intersection of strategic management and supply chain management. Industrial Marketing Management 33 (1), 51-56.

Küchlin, W., Sinz, C., 2000. Proving consistency assertions for automotive product data management. Journal of Automated Reasoning 24, 145-163.

Lambert, D., Stock, J.R., Ellram, L.M., 1993. Fundamentals of Logistics Management, International ed. McGraw Hill. Chapter 7, pp. 233-237.

Lee, H.L., 2004. The triple - a supply chain. Harvard Business Review 83, 102-112.

Li, S., Ragu-Nathan, B., Ragu-Nathan, T.S., Rao, S.S., 2004. The impact of supply chain management practices on competitive advantage and organizational performance. Omega 34 (2), 107-124.

Marlow, P.B., Casaca, Ana C.P., 2003. Measuring lean ports performance. International Journal of Transport Management 1, 189-202.
Mendonça, M.C., Dias, J.C.Q., 2007. Postponement in the logistical systems of new automobiles marketed in Portugal: the Brands and quality. Total Quality Management \& Business Excellence 18 (6), 691-696.

Min, H., Galle, W.P., 1999. Electronic commerce usage in business-to-business purchasing. International Journal of Operations and Production Management 19 (9), 909-921.

Mintzberg, H., 1979. An emerging strategy of direct research. Administrative Science Quarterly 24 (4), 582-589.

Naylor, J. Bin, Mohamed, Naim, Berry, D., 1999. Leagility: integration the lean and agile manufacturing paradigms in the total supply chain. International Journal of Production Economics 62, 107-118.

Olhager, J., 2003. Strategic position of the order penetration point. International Journal Production Economics 85, 319-329.

Paixão, A.C., Marlow, P.B., 2002. Strengths and weakness of short sea shipping. Marine Policy 26 (3), 167-178.

Perez-Labajos, C., Blanco, Beatriz, 2004. Competitive policies for commercial sea ports in the EU. Marine Policy 28 (6), 553-556.

Rajeshkumar, B.C., Rameshbabu, T., 2006. Evaluation of logistics related policies between two different levels of the supply chain network - a case study. Annals of Operations Research 143 (1), 77-89.

Rodrigue, J.-P., 1999. Globalization and the synchronization of transport terminals. Journal of Transport Geography 7, 255-261.

Runhaar, Hens, Heijden, Rob van der, 2005. Public policy intervention in freight transport costs: effects on printed media logistics in the Netherlands. Transport Policy 12 (1), 35-46.

Silveira, G., Borenstein, D., Fogliatto, S. Flávio, 2001. Mass customization: literature review and research directions. International Journal of Production Economics 72, 1-13.

Skipworth, H., Harrison, A., 2006. Implications of form postponement to manufacturing a customized product. International Journal of Production Research 44 (8), 1627-1652.

Stopford, M., 1997. Maritime Economics, second ed. Rutledge, London and New York. Chapter 9, pp. 333-335; Chapter 11, pp. 388-408.

Su, J.C.P., Chang, Y.-L., Ferguson, M., 2005. Evaluation of postponement structures to accommodate mass customization. Journal of Operations Management 23, 305318.

Torbianelli, Vittorio A., 2000. When the road controls the sea: a case study of ro-ro transport in the Mediterranean. Maritime Policy Management 27 (4), 375-389.

Yang, B., Burns, N., 2003. Implications of postponement for the supply chain. International Journal of Production Research 41 (9), 2075-2090.

Yin, R.K., 1994. Case Study Research Design and Methods, second ed. Sage, London. Chapter 1, pp. 14-15; Chapter 2, p. 21; Chapter 3, pp. 62-65 